\title{
Ghosting and breadcrumbing: prevalence and association with online dating behavior among young adults
}

\section{Ghosting y breadcrumbing: prevalencia y relaciones con los comportamientos vinculadas a las citas online entre jóvenes adultos}

\author{
Raúl Navarro, Elisa Larrañaga, Santiago Yubero, Beatriz Villora \\ Universidad de Castilla-La Mancha, España
}

\begin{abstract}
The present study is part of a large study analyzing the prevalence of ghosting and breadcrumbing in sample of Spanish adults aged between 18 and 40 years. The study was split into different papers to better organize and understand the data obtained. The present paper investigated the prevalence of ghosting and breadcrumbing and associations between ghosting and breadcrumbing behavior and online dating practices. The results showed that half the participants were unfamiliar with the terms ghosting and breadcrumbing. However, approximately two in every 10 participants reported having experienced and initiated ghosting, and slightly more than three in every 10 participants had experienced or initiated breadcrumbing in the last 12 months. Regression analyses showed that the use of online dating sites/apps, more short-term relationships, and practicing online surveillance increase the likelihood of experiencing, as well as initiating, ghosting and breadcrumbing.
\end{abstract}

Keywords: ghosting, breadcrumbing, young adults, online dating, mobile apps

\section{Resumen}

El presente estudio es parte de un gran estudio que analiza la prevalencia del ghosting y el breadcrumbing en una muestra de adultos españoles con edades entre 18 y 40 años. El estudio se ha dividido en diferentes manuscritos para permitir una mejor organización y comprensión de los datos obtenidos. En el presente manuscrito, se examina la prevalencia del ghosting y el breadcrumbing y se exploran las relaciones de estas conductas con la búsqueda de citas a través de apps o sitios web. Los resultados mostraron que la mitad de los participantes no estaban familiarizados con los términos ghosting y breadcrumbing, aunque aproximadamente dos de cada 10 participantes informaron haber sufrido e iniciado ghosting, y algo más de tres de cada 10 participantes habian sufrido o iniciado breadcrumbing en los últimos 12 meses. Los análisis de regresión revelaron que el uso de sitios/aplicaciones de citas, un mayor número de relaciones a corto plazo y el hecho de vigilar la conducta online de la pareja aumentan la probabilidad de sufrir, pero también de ejercer, ghosting y breadcrumbing.

Palabras clave: ghosting, breadcrumbing, adultos jóvenes, citas online, aplicaciones móviles.

Please cite this article as: Navarro, R., Larrañaga, E., Yubero, S., \& Villora, B. (2020). Ghosting and breadcrumbing: prevalence and relations with online dating behaviors among young adults. Escritos de Psicología - Psychological Writings, 13(2), 46-59. https://doi.org/1024310/espsiescpsi.v13i2.9960 


\section{Introduction}

Mobile applications (apps) have developed and become the most widespread method to find dates and meet romantic partners (Hobbs, Owen \& Gerber, 2017). Ten years ago, heterosexual and gay people met dating partners in bars and clubs or through friends, workmates and family. However, since 2009, the use of more traditional methods of meeting dating partners has drastically declined, whereas meeting partners online has continued to grow (Prestage et al., 2015; Rosenfeld, Thomas \& Hausen, 2019). In Spain, four in every ten Internet users employed dating platforms in 2018, seven in every ten users accessed them through mobile apps, and $62 \%$ of users were men versus only $38 \%$ of women. In age terms, those visiting these pages were 41 years on average, which is slightly younger than that of the average Internet user (43.6 years). Gay dating users were those who spent more time on these services on average. On the days they accessed, they spent about 30 minutes on average, which is 3-fold longer than heterosexual users, who invested only 10 minutes (Growth from knowledge, 2019).

During their lifetimes, both men and women have embraced online dating platforms to search for a new companion, a hookup, or even a long-term relationship (Abramova, Baumann, Krasnova \& Buxmann, 2016; Menking, Robles, Wiley, Gonzaga, 2015). New media technologies offer access to more potential dates, permit encounters with people who we would not normally meet in our day-to-day lives, allow the use of computer-mediated communication to learn a wide range of facts about partners before meeting them in person, increase the ease with which affection or sexual preferences can be expressed, and offer diverse tools for negotiating stages of their love/sex relationships (Finkel, Eastwick, Karney, Reis \& Sprecher, 2012; Meenagh, 2015). However, new media technologies also have downsides, such as the gradual feeling of discontent and pessimism about finding a mate (Pronk \& Denissen, 2019), gamification of relationships, lack of romance and empathy on dating apps, and a growing use of behaviors like "ghosting", "slow fading", "benching", "breadcrumbing" or "haunting" (Cook, 2020). These behaviors illustrate how people are using technologies to flirt, initiate, maintain or end relationships. An analysis of all these practices seems crucial for us to be able to understand and learn the way that dating is done in the present-day (Stoicescu, 2019). However, very few published studies have examined these phenomena. Therefore, the primary aim of the present study was to examine the prevalence of two of these digital tactics (ghosting and breadcrumbing) among young adults and its relation with using online dating and online dating practices.

\section{Ghosting and Breadcrumbing}

Ghosting is conceptualized as a strategy to end a dating or romantic relationship that emerges in the digital age as a method to avoid direct confrontation and to discuss the relationship status with the partner (LeFebvre, 2017). Specifically, ghosting refers to "instances where the disengager (the partner who initiates a breakup) unilaterally dissolves a romantic relationship by avoiding online and offline contact with the recipient (the partner who is broken up with)" (Koessler, Kohut \& Campbell, 2019, p.1). Ghosting occurs through one technological means or many; e.g., not responding to phone calls or text messages, no longer following partners or blocking partners on social networks platforms. Ghosting differs from other relationship dissolution strategies insofar as an explicit explanation or announcement of termination to the breakup receiver is lacking (Koessler, Kohut \& Campbell, 2019). In other words, ghosting takes place without the ghosted mate immediately knowing what has happened, and being left to manage and understand what the partner's lack of communication means (Freedman, Powell, Le \& Williams, 2019) without being able to obtain closure (LeFebvre et al., 2019).

The term ghosting was originally posted in the 2006 Urban dictionary, has gained increasing attention in recent times, and was chosen as one of the top words in 2015 by the Collins English Dictionary (The Telegraph, 2015). Then in 2016, a new relationships trend in the dating scene emerged: "breadcrumbing" (The New York Times, 2016). The term "breadcrumbing" originates from the noun "breadcrumbs", which means "very small pieces of dried bread, especially used in cooking" (Cambridge Dictionary, 2019). Breadcrumbing, also known as Hansel and Grettelling, has been defined by Urban Dictionary as "the act of sending out flirtatious, but non-committal text messages (.i.e "breadcrumbs"), in order to lure a sexual partner without expending much effort" or "when the "crush" has no intentions of taking things further, but they like the attention. So they flirt here or there, send DMs/texts just to keep the person interested, knowing damn well they're staying single" (Urban dictionary, 2019). Breadcrumbers do not definitely stop calling, but sporadically send DM or text messages, give an occasional wink or a like in a social network, such as Instagram, and just frequently enough so that the receiver does not lose interest, but not too much so that relationships do not progress. Breadcrumbing is not such a clear dissolution strategy as ghosting is because, although breadcrumbing can happen when there has been a break up, but the initiator does not want to let the partner go, it is also a way to keep a date on "hold" 
and is a type of social dynamics where breadcrumbers are not really attracted to the other person, but are interested in staying relevant/attractive to others (The New York Times, 2016). In any case breadcrumbing, like ghosting, is a strategy used by people to negotiate their romantic/sexual relationships.

\section{Research gaps: Lack of Empirical Studies on Ghosting, Breadcrumbing and Online Dating Use.}

Although flirting, ignoring someone or dissolving a relationship are no recent phenomena, the proliferation of dating apps, such as Tinder, Grindr, eHarmony or Bumble, influences traditional processes of relationship dissolution or maintenance (Koessler et al., 2019). There is still very little empirical evidence for new flirting, ignoring, rejection or breakup strategies. However, more studies about adult ghosting experiences have appeared in recent years, at least in the United States. As for the prevalence of ghosting, the survey conducted with US adults by YouGov and the Huffington Post found that around 13\% of the 1000 participants were ghosted by a partner and $11 \%$ informed ghosting a partner (Moore, 2014). In a series of studies, Freedman et al. (2019) found in a first sample of 554 US adults that $25.3 \%$ reported they had been ghosted and $21.3 \%$ had ghosted a dating partner. In a second sample of 747 participants, $23 \%$ informed that they had been ghosted and $18.9 \%$ reported having ghosted a dating partner. Likewise, with a sample of 99 US university students, LeFebvre et al (2019) observed how 29.3\% were ghosters (initiators) and 25.3\% were ghostees (non-initiators). More recently, Koessler et al. (2019) conducted a study with 333 US adults to find that $72 \%$ of the participants informed that they had been ghosted by a partner, whereas $64.5 \%$ of participants reported ghosting a partner.

Even though research on ghosting prevalence is increasing, breadcrumbing prevalence has not yet been empirically examined. Considering the available data on how often ghosting occurs, we can assume that at a time where many relationships begin by means of mobile apps, breadcrumbing is a phenomenon that more and more people will face. So empirical examinations are necessary to understand these digital behaviors, their incidence and the variables related to them. Therefore, it is necessary to estimate breadcrumbing prevalence among young adults and to compare it to ghosting prevalence.

Given that ghosting and breadcrumbing can negatively impact those who experience or enact them (Authors, 2019; Koessler et al., 2019), research is necessary the factors that increase or lower the likelihood of adults becoming initiators or recipients of these types of online behaviors. Of the empirical studies on ghosting, some have served to conceptualize the phenomenon and explain it as a strategy to escape unwanted relationships without ever having to breakup (LeFebvre et al., 2019). Other studies have begun to analyze when ghosting is used and the type of tactics that it includes. For example, Freedman et al. (2019) examined how implicit theories of relationships were associated with ghosting. They found that participants with stronger destiny beliefs (i.e. steady and invariable relationships), compared to those with weaker destiny beliefs, reported more acceptability of ghosting behaviors, informed more ghosting intentions, and had previously used ghosting. On the contrary, the participants with stronger growth beliefs (i.e. relationships are changing and can develop over time), compared to those with weaker growth beliefs, reported less acceptability of ghosting behaviors and fewer intentions of using ghosting. Koessler et al. (2019) analyzed differences in communication breakup tactics according to the adopted breakup strategy (ghosting or direct conversation). They found that ghosting breakups were characterized by a more widespread use of avoidance/withdrawal and distant/mediated communication tactics, and by fewer open confrontation and positive tone tactics. Manning, Denker and Johnson [Manning, Denker \& Johnson, 2019] conducted a qualitative study with U.S adults to understand how people describe uncertainties and concerns related to ghosting and what motives or rationales are used to justify ghosting. Participants described ghosting as wrong, immature, and sometimes hurtful when someone have done it to them. However, when they have initiated ghosting they often justify it as a way of protecting themselves after being disrespected, experiencing aggressiveness or even harassment.

To date however, no study has explicitly analyzed the use of online dating and online dating practices among young adults who have been initiators or recipients of ghosting and breadcrumbing. Understanding the characteristics and behaviors of adults' use and misuse of online dating sites/apps, and how such characteristics and behaviors differ across initiators or recipients of ghosting and breadcrumbing, are important for comprehending how and when people adopt digital strategies to cut or maintain relationships. Although no research has examined the use of online dating sites and online dating practices, we turn our attention to research that examines the associations between Internet use and different forms of victimization and perpetration. Previous studies that have investigated Internet use report a significant association between more Internet use (i.e. more time spent online and using diverse online activities more) and an increased probability of encountering risky situations online, such as peer aggression (Martínez-Ferrer, Moreno \& Musitu, 2018), cyberbullying (Gini, Marino, Xie, Pfetsch \& Pozzoli, 2019), doxing (Chen, Cheung \& Chan, 2019), cyber dating abuse (Víllora, Navarro, Yubero, 
2019) or grooming (Gómez, Rial, Braña, Golpe \& Varela, 2017). It is, therefore, reasonable to suggest that the use of online dating sites/apps, and the time spent on them, may increase the likelihood of being exposed or enacting ghosting and breadcrumbing.

The number and type of relationships initiated through online dating sites may also play an important role in ghosting and breadcrumbing. For example, Koessler et al (2019) found that the relationships terminated through ghosting were shorter and characterized by less commitment than those terminated by direct conversation. It is, therefore, feasible that ghosting and breadcrumbing behaviors, and being ghosted or breadcrumbed, will be more likely among those adults who start more short-term/casual relationships.

Online dating includes several decisions and behaviors that should be taken into account when analyzing digital dissolution or maintenance strategies. The speed chosen to meet an online dating partner face-to-face (shifting offline) is one of the decisions that online daters must make (Blackhart, Fitzpatrik, Williamson, 2014). While online daters differ in terms of their relationships goals, the shift from computer-mediated communication to face-to-face meetings is the riskiest step in the process because when online partners meet for the first time, they might feel disappointed because the online alter ego may be not identical to the people who created it (Lawson \& Leck, 2006). The researchresults about modality shifting indicate that online daters may benefit from meeting their partner in person after a brief online communication period, whereas continuing online interaction for longer time periods may have negative outcomes, such as worse perceptions of intimacy and composure (Ramirez, Sumner, Fleuriet \& Cole, 2014).

Although no research has examined how the length of time before meeting an online dating partner in person may be related to ghosting and breadcrumbing behaviors, we believe that the people who communicate online for longer periods of time before face-to-face meetings may initiate or be recipients of ghosting and breadcrumbing to a greater extent than those communicating online for shorter periods of time. Those who switch early are able to cut the relationship during the first or subsequent encounters via direct conversation, whereas those who spend more time interacting online may create more ties between online daters, which might make breaking up the relationship difficult, and they might opt for ghosting or breadcrumbing strategies when expectations about one's online partner are not met.

Among online dating behaviors, online surveillance through social networking serves to gain awareness of a date's offline and/or online behaviors, and may occur during the escalation, maintenance or breaking up of relationships (Tokunaga, 2011). Online surveillance is a tool that can inform about feelings for, or decisions about, a relationship (Fox, Orbon \& Warber, 2014). Indeed research has found that online surveillance offers people a way to reduce or manage uncertainty by collecting information about romantic partners (Tong, 2013). However, people who get involved in online surveillance are more inclined to question their relationship and experience a better chance of ending relationships compared to people who less often engage in surveillance (Brody, LeFebvre \& Blackburn, 2016). Online surveillance is also a source of tension and conflict between partners, which can lead the relationship to end (Fox \& Warber, 2014). As a result, we predict that engaging in online surveillance may increase the likelihood of also engaging in ghosting and breadcrumbing as initiators and receivers.

The Present Study.

This study is part of a larger project analyzing ghosting and breadcrumbing experiences. In this paper, the aim was to analyze ghosting and breadcrumbing prevalence in initiator and recipient roles, and to examine differences in the frequency of this type of digital behaviors according to several socio-demographic variables: gender, sexual orientation, level of education, relationship status. We also conducted an analysis of the relationships of ghosting and breadcrumbing behaviors with: use of online dating sites/apps; time spent on online dating sites/apps; number and type of relationships initiated through online dating sites/apps; length of time before meeting an online dating partner in person; online surveillance. Our main research objectives were as follows:

Objective 1: to examine the prevalence and frequency of ghosting and breadcrumbing in both the initiator and recipient roles.

Objective 2: to examine whether an association exists between ghosting and breadcrumbing and the use of online dating sites/apps. We hypothesized that ghosting and breadcrumbing would be more likely to be experienced and initiated among those young adults who use online dating sites/apps (H1).

Objective 3: to examine whether ghosting and breadcrumbing is related to the time spent using online dating sites/apps. We hypothesized that ghosting and breadcrumbing would be more likely to be experienced and initiated among those young adults who spent more time employing online dating sites/ apps (H2). 
Objective 4: to analyze whether ghosting and breadcrumbing are associated with the number and type of relationships initiated online. We hypothesized that more short-term relationships would increase the likelihood of experiencing or initiating ghosting and breadcrumbing, whereas long-term relationships would lower the likelihood of ghosting and breadcrumbing $(\mathrm{H} 3)$.

Objective 5: to examine whether ghosting and breadcrumbing are related to the length of time left before meeting an online dating partner in person. We hypothesized that ghosting and breadcrumbing would be more likely to occur among those adults who interact online for longer periods of time before meeting someone in person $(\mathrm{H} 4)$.

Objective 6: to analyze whether ghosting and breadcrumbing are associated with online surveillance. We hypothesized that ghosting would be more likely to be experienced and initiated by those adults who engage in online surveillance of their partner (H5).

\section{Study Design and Participants}

\section{Method}

Convenience and snowball sampling was used to recruit the participants of the present study. The URL to an anonymous online survey was first sent among doctoral students of a medium-sized university in central Spain. Students were asked to send the link to the survey to family members and acquaintances who they knew had a mobile phone and Internet access and had one or more short-term or long-term relationships regardless of their current sentimental status. The final sample included 626 participants (male $=29.64$ years; $S D=8.84)$. An equivalent number of male $(n=303)$ and female $(n=323)$ adults completed the survey, of whom $79.4 \%$ had a higher level of education. In addition, $82.9 \%$ of the sample indicated being heterosexual and 17.1 being lesbian, gay or bisexual (LGB). On average, the participants had experienced two relationships $(M=2.23, S D=0.74)$ in their dating history, which ranged from one to six relationships, and $390(62.3 \%)$ indicated being in relationships at the time they answered the online survey.

\section{Procedures}

After obtaining their informed consent, we asked the adults who clicked the link to an online survey to fill out a self-administered questionnaire. We informed the participants that they could assess the questionnaire once, and we ensured the respondents' anonymity. The Clinical Research Ethics Committee of Virgen de La Luz Hospital in Cuenca approved the study protocol (PI0519).

\section{Measurements}

Demographics. The participants reported their age, gender, sexual orientation, level of education, current relationship status and number of relationships in their dating history. Gender was a dichotomous variables where $1=$ female and $2=$ male. Age was transformed in a dichotomous variables where $1=$ emerging adults (18-25 years old) and $2=$ young adults (26-40 years old). Sexual orientation was a dichotomous variables where $1=$ heterosexual participants and 2 : lesbian, gay and bisexual participants. Level of educations had three levels: $1=$ Primary Education, $2=$ Secondary education, and $3=$ Higher Education. Current sentimental situation was a dichotomous variable where $1=$ single and $2=$ have a partner.

Ghosting experiences. Participants were first asked if they were familiar with the term "ghosting". After informing about familiarity with the term, a definition was provided in order to avoid unfamiliarity and previous to self-report this type of experiences. Following LeFebvre et al. (2019) "ghosting" was defined as follows: unilaterally ceasing all communication (temporarily or permanently) with someone with whom some kind of romantic relationship is maintained. It is a way to end the relationship (sudden or gradual) in which all contact with that person is cut off or their attempts to communicate with the one who initiated it are ignored. "Ghosting" commonly occurs through one technological mean or many, for example, not responding to phone calls or WhatsApp messages, ceasing to follow or block it on social network sites). After the definition, we asked the participants to indicate whether someone who they considered their dating partner had ghosted them and if they had ghosted someone in the last year. Items scored on a 5-point scale: 0 (never); 1 (not in the last year, but before); 1 (once or twice); 3 (3 to 5 times); 4 (more than 5 times).

Breadcrumbing experiences. Participants were first asked if they were familiar with the term "breadcrumbing". After informing about familiarity with the term, a definition was provided in order to avoid unfamiliarity and previous to self-report this type of experience. The definition used was: "breadcrumbing" literally refers to leaving bread crumbs so that someone can follow the trail. Breadcrumbers do not stop talking on WhatsApp, send random DMs or text messages, or give an occasional like on a social 
network site to not ignore the other person at all, but the relationship does not progress. Breadcrumbing can happen when there has been a break up, but the initiator does not want to let the partner go. It is also a way to maintain a date on "hold" and is a type of social dynamics where breadcrumbers are not really attracted to the other person, but are interested in staying relevant/attractive for others. After the definition, we asked participants to indicate whether someone who they considered their dating partner had breadcrumbed them and if they had breadcrumbed someone in the last year. Items scored on a 5-point scale: 0 (never); 1 (not in the last year, but before); 2 (once or twice); 3 (3 to 5 times); 4 (more than 5 times).

Online dating use and practices related to online dating. We used some of the questions included in the Online Dating Inventory developed by Blackhart, Fitzpatrick and Williamson (2014). Specifically, the participants answered questions about whether they have ever used online dating sites/apps (yes or no), the time they spent per day using online dating sites/apps ( $1=$ less than 30 minutes per day, $5=$ more than 3 hours per day), the number of short-term and long-term relationships developed through online dating sites/apps ( 0 to more than 3 ), the length of time before meeting an online dating partner in person (0-1 weeks to 2-3 months), and whether they had monitored partners and met online via social networking sites $(0=$ never, $7=$ several times). Variables with more than two categorical options were transformed into dichotomous variables. Time spent using online dating sites/apps was dichotomized into $1=1$ hour or less per day and $2=$ more than 1 hour per day. Short-term and long-term relationships were dichotomized into $1=$ between 0 and 3 and $2=$ more than 3 . Amount of time before meeting offline was dichotomized into $1=$ between 0 and 4 weeks and $2=$ more than 4 weeks. Online surveillance was introduced as a continuous variable.

\section{Statistical analysis}

First, we analyzed the general descriptive about all the study variables. Second, we calculated the mean frequency and the percentages of ghosting and breadcrumbing for both those who started them and the recipients of these practices. Third, we analyzed any differences in frequency according to the herein included socio-demographic variables. To do so, we used the Student's t-test for the variables with only two categories, and the Welch $\mathrm{F}$ test for the variables with more than two categories. We employed Games-Howell post hoc test to find any differences among groups. Finally, considering of measure of ghosting and breadcrumbing as an ordinal approximation of a continuous variable, we ran a linear regression analysis to check the relation linking ghosting and breadcrumbing, use of online dating sites/ apps and online dating practices. In all cases, Levene's test for the equality of variances confirmed the equality of variances which, in turn, confirmed the homoscedasticity assumption. We used the SPSS 24.0 statistical package for all the analyses.

\footnotetext{
Results

Analysis of Ghosting and Breadcrumbing Prevalence among initiators and recipients.

Table 1 provides the participants' characteristics and the descriptives of online dating use. We asked the participants if they knew the terms ghosting and breadcrumbing. Of the 626 participants, $398(63.6 \%)$ stated that they were unfamiliar with the term ghosting, and $539(86.1 \%)$ were unfamiliar with the term breadcrumbing. Nonetheless after reading the definition of both these terms, 19.3\% (121) stated having suffered ghosting and $23.2 \%$ (145) indicated they had initiated ghosting at least once in the last year. Of these participants, $2.9 \%$ (18) acknowledged that they had suffered ghosting more than 5 times in the past year and $2.9 \%(18)$ had initiated it more than 5 times in the last 12 months. For breadcrumbing, $35.6 \%$ (223) pointed out having suffered it, while $36.7 \%(230)$ had initiated it, and both at least once in the last year. Of these, $5.1 \%(32)$ had been a victim of breadcrumbing more than 5 times and $6.9 \%(43)$ had initiated it more than 5 times in the past year.
} 
Table 1

Socio-demographic characteristics of the sample and online dating use descriptives $(n=626)$

\begin{tabular}{|c|c|c|c|c|}
\hline Socio-demographic variables & $\mathrm{n}$ & $\%$ & Mean & SD \\
\hline Age & & & 28.81 & 7.21 \\
\hline \multicolumn{5}{|l|}{ Gender } \\
\hline Male & 303 & 48.4 & & \\
\hline Female & 323 & 51.3 & & \\
\hline \multicolumn{5}{|l|}{ Sexual orientation } \\
\hline Heterosexual & 519 & 82.9 & & \\
\hline Lesbian, gay or bisexual & 107 & 17.1 & & \\
\hline \multicolumn{5}{|l|}{ Level of education } \\
\hline Primary Education & 19 & 3.0 & & \\
\hline Secondary Education & 110 & 17.6 & & \\
\hline Higher Education & 497 & 79.4 & & \\
\hline \multicolumn{5}{|l|}{ Current sentimental status } \\
\hline Single & 236 & 37.7 & & \\
\hline Have a partner & 390 & 62.3 & & \\
\hline \multicolumn{5}{|l|}{ Online dating } \\
\hline \multicolumn{5}{|l|}{ Use of online dating sites/apps } \\
\hline No & 274 & 43.8 & & \\
\hline Yes & 352 & 56.2 & & \\
\hline \multicolumn{5}{|c|}{ Time spent using online dating sites/apps } \\
\hline 1 hour or less per day & 565 & 90.3 & & \\
\hline More than 1 hour per day & 61 & 9.7 & & \\
\hline \multicolumn{5}{|c|}{ Short-term relationships from online dating } \\
\hline Between 0 and 3 & 576 & 92.0 & & \\
\hline More than 3 & 50 & 8.0 & & \\
\hline \multicolumn{5}{|c|}{ Long-term relationships from online dating } \\
\hline Between 0 and 3 & 613 & 97.0 & & \\
\hline More than 3 & 13 & 2.1 & & \\
\hline \multicolumn{5}{|c|}{ Amount of time before meeting offline (ATM) } \\
\hline Between 0 and 4 weeks & 565 & 90.3 & & \\
\hline More than 4 weeks & 61 & 9.7 & & \\
\hline Online surveillance & & & 3.07 & 2.14 \\
\hline
\end{tabular}

Table 2 offers the disaggregated prevalence data according to the response options and the mean score for both ghosting and breadcrumbing, distributed into initiators and receivers. Breadcrumbing frequency was greater than that for ghosting for both the initiator and receiver roles.

Table 2

\begin{tabular}{lcccc} 
Prevalence and type of experience $(\mathrm{N}=626)$ & \\
\hline Ghosting and Breadcrumbing experiences & $\begin{array}{c}\text { Ghosting } \\
\text { receivers }\end{array}$ & $\begin{array}{c}\text { Ghosting } \\
\text { initiators }\end{array}$ & $\begin{array}{c}\text { Breadcrumbing } \\
\text { receivers }\end{array}$ & $\begin{array}{c}\text { Breadcrumbring } \\
\text { initiators }\end{array}$ \\
\hline Never & $369(58.9 \%)$ & $383(61.2 \%)$ & $274(43.8 \%)$ & $276(44.1 \%)$ \\
Not in the last year, but before & $136(21.7 \%)$ & $98(15.7 \%)$ & $129(20.6 \%)$ & $120(9.2 \%)$ \\
Once or twice & $76(12.1 \%)$ & $90(14.4 \%)$ & $120(19.2 \%)$ & $116(18.5 \%)$ \\
3 to 5 times & $27(4.3 \%)$ & $37(5.9 \%)$ & $71(11.3 \%)$ & $71(11.3 \%)$ \\
More than 5 times & $18(2.9 \%)$ & $18(2.9 \%)$ & $32(5.1 \%)$ & $43(6.9 \%)$ \\
M (SD) & $1.72(1.07)$ & $1.75(1.13)$ & $2.15(1.28)$ & $2.20(1.35)$ \\
\hline
\end{tabular}

Differences in the Frequency of Ghosting and Breadcrumbing according to the socio-demographic variables

We analyzed the frequency of ghosting and breadcrumbing in both the initiator and receiver roles according to the examined socio-demographic variables (see Tables 3 and 4). The ghosting results only revealed significant differences in two of the analyzed variables. The LGB participants informed having experienced more ghosting frequency in the past year than the heterosexual participants. The single participants indicated having suffered and initiated more ghosting in the last 12 months than the participants who had a partner when they completed the questionnaire. We found no significant differences for gender, age or level of education. 
Table 3

Frequency differences in ghosting according to socio-demographic variables $(\mathrm{N}=626)$

\begin{tabular}{|c|c|c|c|c|}
\hline \multirow[b]{2}{*}{ Socio-demographic variables } & \multicolumn{2}{|c|}{ Ghosting receivers } & \multicolumn{2}{|c|}{ Ghosting initiators } \\
\hline & $\begin{array}{c}\text { Frequency } \\
M(S D)\end{array}$ & $t / F$ & $\begin{array}{c}\text { Frequency } \\
M(S D)\end{array}$ & $\mathrm{t} / \mathrm{F}$ \\
\hline \multicolumn{5}{|l|}{ Age } \\
\hline $18-25$ years (Emerging adults) & $1.81(1.16)$ & \multirow{2}{*}{1.68} & $1.79(1.19)$ & \multirow{2}{*}{0.73} \\
\hline $26-40$ years (Young adults) & $1.66(1.01)$ & & $1.72(1.08)$ & \\
\hline \multicolumn{5}{|l|}{ Gender } \\
\hline Female & $1.69(1.03)$ & \multirow{2}{*}{-0.74} & $1.77(1.15)$ & \multirow{2}{*}{0.51} \\
\hline Male & $1.75(1.12)$ & & $1.72(1.10)$ & \\
\hline \multicolumn{5}{|l|}{ Sexual orientation } \\
\hline Heterosexual & $1.67(1.02)$ & \multirow{2}{*}{$\begin{array}{c}-2.47^{\star} \\
d=-0.23\end{array}$} & $1.71(1.09)$ & \multirow{2}{*}{-1.67} \\
\hline Lesbian, gay, bisexual & $1.94(1.28)$ & & $1.92(1.30)$ & \\
\hline \multicolumn{5}{|l|}{ Level of education } \\
\hline Primary Education & $1.79(0.91)$ & \multirow{3}{*}{0.37} & $1.89(1.32)$ & \multirow{3}{*}{0.52} \\
\hline Secondary Education & $1.79(1.11)$ & & $1.83(1.29)$ & \\
\hline Higher Education & $1.70(1.07)$ & & $1.73(1.08)$ & \\
\hline \multicolumn{5}{|l|}{ Current sentimental situation } \\
\hline Single & $1.92(1.21)$ & \multirow{2}{*}{$\begin{array}{l}3.70^{\star * *} \\
d=0.30\end{array}$} & $1.66(1.06)$ & \multirow{2}{*}{$\begin{array}{l}-3.37^{* * *} \\
d=-0.29\end{array}$} \\
\hline Have a partner & $1.59(0.96)$ & & $2.01(1.29)$ & \\
\hline
\end{tabular}

Note: $\mathrm{t}$ (Student's t-test), F (Welch F test), d (Cohen's d) ${ }^{*} p<.05 ;{ }^{* *} p<.01 ;{ }^{* \star *} p<.001$

The breadcrumbing results revealed significant differences in three of the studied variables. Specifically, the younger age group (emerging adults) had experienced and initiated breadcrumbing more frequently in the last year than the older age group (young adults). The LGB participants had experienced and performed breadcrumbing more frequently in the past 12 months than the heterosexual participants. Single people had more frequently suffered and performed breadcrumbing in the past 12 months than the people with a partner when they conducted the questionnaire. No significant differences appeared for gender and level of education.

Table 4

Frequency differences in breadcrumbing according to socio-demographic variables $(\mathrm{N}=626)$

\begin{tabular}{|c|c|c|c|c|}
\hline \multirow[b]{2}{*}{ Socio-demographic variables } & \multicolumn{2}{|c|}{ Breadcrumbing receivers } & \multicolumn{2}{|c|}{ Breadcrumbing initiators } \\
\hline & $\begin{array}{c}\text { Frequency } \\
M(S D)\end{array}$ & $t / F$ & $\begin{array}{c}\text { Frequency } \\
M(S D)\end{array}$ & $t / F$ \\
\hline \multicolumn{5}{|l|}{ Age } \\
\hline $18-25$ years (Emerging adults) & $2.27(1.32)$ & \multirow{2}{*}{$\begin{array}{c}1.93^{*} \\
d=0.15\end{array}$} & $2.33(1.34)$ & \multirow{2}{*}{$\begin{array}{c}2.00^{*} \\
d=0.16\end{array}$} \\
\hline $26-40$ years (Young adults) & $2.07(1.24)$ & & $2.11(1.35)$ & \\
\hline \multicolumn{5}{|l|}{ Gender } \\
\hline Female & $2.10(1.26)$ & \multirow{2}{*}{-0.92} & $2.15(1.33)$ & \multirow{2}{*}{-0.87} \\
\hline Male & $2.19(1.29)$ & & $2.24(1.35)$ & \\
\hline \multicolumn{5}{|l|}{ Sexual orientation } \\
\hline Heterosexual & $2.06(1.22)$ & \multirow{2}{*}{$\begin{array}{l}-4.08^{\star \star *} \\
d=-0.41\end{array}$} & $2.13(1.31)$ & \multirow{2}{*}{$\begin{array}{c}-2.88^{* *} \\
d=-0.29\end{array}$} \\
\hline Lesbian, gay, bisexual & $2.61(1.44)$ & & $2.54(1.47)$ & \\
\hline \multicolumn{5}{|l|}{ Level of education } \\
\hline Primary Education & $1.79(1.08)$ & \multirow{3}{*}{1.55} & $1.89(1.28)$ & \multirow{3}{*}{0.52} \\
\hline Secondary Education & $2.10(1.27)$ & & $2.24(1.46)$ & \\
\hline Higher Education & $2.18(1.29)$ & & $2.21(1.33)$ & \\
\hline \multicolumn{5}{|l|}{ Current sentimental situation } \\
\hline Single & $2.50(1.41)$ & \multirow{2}{*}{$\begin{array}{l}5.33^{\star * *} \\
d=0.43\end{array}$} & $2.54(1.49)$ & \multirow{2}{*}{$\begin{array}{l}4.93^{\star * *} \\
d=0.39\end{array}$} \\
\hline Have a partner & $1.94(1.15)$ & & $2.00(1.21)$ & \\
\hline
\end{tabular}

Note: $t$ (Student's t-test), F (Welch F test), d (Cohen's d), ${ }^{*} p<.05 ;{ }^{* *} p<.01 ;{ }^{* \star *} p<.001$

Association among ghosting, breadcrumbing, and using online dating sties/apps and practices related to online dating

To examine the associations among use of online dating sites/apps, practices related to online dating and initiating/receiving ghosting/breadcrumbing, we performed linear regression analyses after introducing the socio-demographic variables as the control variables. The obtained results are provided in Table 5, which indicate that use of online dating sites/apps, more short-term relationships and practicing online surveillance implied being more likely to suffer, but also initiate, ghosting and breadcrumbing. We found a positive relation between spending more time on using online dating sites/apps and suffering/ initiating ghosting, but not for breadcrumbing. For the control variables, the results revealed that being 
male increased the likelihood of initiating ghosting. Being in the 26-40 year-old age group (young adults) increased the likelihood of suffering ghosting more frequently. Finally, being single increased the likelihood of performing breadcrumbing with others.

Table 5

Multiple regression analyses to examine the associations among using online dating sites/apps, practices related to online dating sites/apps and ghosting and breadcrumbing experiences.

\begin{tabular}{|c|c|c|c|c|c|c|c|c|c|c|c|c|}
\hline \multirow{2}{*}{ Variables } & \multicolumn{3}{|c|}{ Ghosting receivers } & \multicolumn{3}{|c|}{ Ghosting initiators } & \multicolumn{3}{|c|}{ Breadcrumbing receivers } & \multicolumn{3}{|c|}{ Breadcrumbing initiators } \\
\hline & B & SEB & $\beta$ & B & SEB & $\beta$ & B & SEB & $\beta$ & B & SEB & $\beta$ \\
\hline \multicolumn{13}{|l|}{ Online dating } \\
\hline Use of online dating & -0.14 & 0.09 & $-0.06^{*}$ & -0.23 & 0.10 & $-0.10^{*}$ & -0.28 & 0.11 & $-0.11^{* *}$ & -0.32 & 0.12 & $-0.11^{* *}$ \\
\hline Time spent & 0.27 & 0.15 & $0.07^{*}$ & 0.41 & 0.16 & $0.11^{*}$ & 0.22 & 0.18 & 0.05 & 0.24 & 0.19 & 0.05 \\
\hline Short-term relationships & 0.64 & 0.18 & $0.16^{\star * *}$ & 0.57 & 0.19 & $0.13^{* * *}$ & 0.67 & 0.22 & $0.14^{* * *}$ & 1.03 & 0.23 & $0.20^{* * *}$ \\
\hline Long-term relationships & 0.27 & 0.29 & 0.03 & 0.24 & 0.31 & 0.03 & -0.19 & 0.35 & -0.02 & -0.48 & 0.37 & -0.05 \\
\hline ATM & 0.01 & 0.14 & 0.04 & 0.02 & 0.15 & 0.07 & -0.11 & 0.17 & -0.02 & -0.09 & 0.18 & -0.02 \\
\hline Online surveillance & 0.13 & 0.19 & $0.25^{\star \star \star}$ & 0.11 & 0.02 & $0.21^{* * *}$ & 0.10 & 0.02 & $0.17^{\star \star \star}$ & 0.11 & 0.02 & $0.17^{\star \star \star}$ \\
\hline \multicolumn{13}{|l|}{ Control variables } \\
\hline Age & -0.12 & 0.06 & $-0.08^{*}$ & -0.01 & 0.06 & -0.06 & -0.01 & 0.07 & -0.06 & -0.01 & 0.08 & -0.07 \\
\hline Gender & -0.07 & 0.08 & -0.03 & -0.18 & 0.08 & $-0.08^{*}$ & -0.02 & 0.10 & -0.09 & -0.03 & 0.10 & -0.01 \\
\hline Sexual orientation & -0.08 & 0.11 & -0.29 & -0.10 & 0.12 & -0.03 & 0.13 & 0.14 & 0.04 & -0.09 & 0.14 & -0.02 \\
\hline Level of education & -0.04 & 0.08 & -0.01 & -0.05 & 0.08 & -0.08 & 0.15 & 0.09 & 0.06 & 0.05 & 0.10 & 0.02 \\
\hline Sentimental situation & -0.14 & 0.08 & -0.06 & -0.07 & 0.09 & -0.03 & -0.34 & 0.10 & -0.12 & -0.29 & 0.11 & $-0.10^{* *}$ \\
\hline R2 (Adj. R2) & \multicolumn{3}{|c|}{$.188(.172)$} & \multicolumn{3}{|c|}{$.160(.143)$} & \multicolumn{3}{|c|}{$.148(.132)$} & \multicolumn{3}{|c|}{$.152(.136)$} \\
\hline $\mathrm{F}$ & \multicolumn{3}{|c|}{$11.826^{\star \star *}$} & \multicolumn{3}{|c|}{$10.635^{\star \star \star}$} & \multicolumn{3}{|c|}{$8.907^{\star \star *}$} & \multicolumn{3}{|c|}{$9.180^{\star \star *}$} \\
\hline
\end{tabular}

Note: Use of online dating (1= Yes; $2=$ No), Time spent (1= 1 hour or less, $2=$ more than 1 hour), Gender (1= male, 2 = female); Age (1=18-25 years, $2=26-40$ years); Sexual orientation ( $1=$ heterosexual, $2=\mathrm{LGB}$ ); Sentimental situation $\left(1=\right.$ single, $2=$ have a partner) ${ }^{*} \mathrm{p}<.05 ;{ }^{* *} \mathrm{p}<.01 ;{ }^{* * *} \mathrm{p}<.001$

\section{Discussion}

The objective of the present study was to analyze the prevalence and differences in the frequency of ghosting and breadcrumbing by considering age, gender, sexual orientation level of education and present sentimental status in a sample of Spanish adults. Another objective was to analyze the relation among ghosting and breadcrumbing, use of online dating sites/apps and practices related to online dating.

\section{Prevalence and Frequency of Ghosting and Breadcrumbing}

Although more than half the participants were unfamiliar with the terms ghosting and breadcrumbing, roughly two in every 10 participants who filled in the online questionnaire informed having suffered and initiated ghosting in the past year. The breadcrumbing data indicated a higher prevalence and revealed that slightly more than three in every 10 participants had suffered it or performed it in the last 12 months. Despite no finding previous studies that had analyzed the prevalence of breadcrumbing, our data agree with former research conducted in the USA, which indicated that between $13 \%$ and $23 \%$ of the respondents reported having suffered ghosting, and between $11 \%$ and $29.3 \%$ had initiated it (Freedman et al., 2019; LeFebvre et al., 2019; Moore, 2014).

Regarding the socio-demographic profile of both the initiators and receivers of both behaviors, the analysis of the differences in the frequency of ghosting and breadcrumbing showed that both were suffered and initiated more among single participants than those with a partner when they answered the questionnaire. This finding could be related to the fact that dating online apps/sites tend to be more widely used by single people or those with an open relationship (Goedel, Mitchell, Krebs\& Duncan, 2017; LeFebvre, 2018). The LGB participants reported suffering and performing breadcrumbing to a greater extent than the heterosexual participants, and they also reported suffering more ghosting, but we found no significant differences with those who admitted having initiated ghosting in the last year. The more widespread use of online dating apps and webs in the LGTB group meant that they were more exposed to Internet risks (Anzani, Di Sarno \& Prunas, 2018; Hahn et al, 2018) apart from ghosting and breadcrumbing. Finally, the participants in the 18-25-year-old age group reported higher scores on breadcrumbing than the participants aged 26-40 years. Despite former studies have demonstrated that the use of online dating apps/sites is more usual among young adults (25-34 year olds) than among emerging adults (18-24 years old), being more exposed to breadcrumbing in emerging adulthood could be related with the fact that this age group is more familiar and use more those apps with which breadcrumbing could take place e.g. Instragram, WhatsApp or Snapchat (labSpain, 2019; Waterloo, Baumgartner, 
Peter \& Valkenburg., 2018). Another explanation for the age differences in breadcrumbing is that older people could be more mature, sincere or have better skills to communicative and treat others without using breadcrumbing. In this line, Manning et al (2019) found that younger people justified their ghosting behaviors as being the result of their young age and immature actions. Older people also saw ghosting as a normative behavior for younger ages but that disappear when people grow older.

\section{Ghosting, Breadcrumbing and Online Dating Use}

The obtained results revealed that using online dating sites/apps increased the chances of suffering or performing ghosting and breadcrumbing $(\mathrm{H} 1)$. This suggests that, at least in part, both these behaviors can form part of the actual online dating dynamics, and that using online sites/apps as a tool to find potential partners can entail more exposure to, or use of, these tactics to break up or maintain the online relationships initiated. Previous studies reveal that using technology, more specifically smartphone dating apps, is related to negative outcomes, such as more exposure to cyber aggression, cyberstalking or risky sexual encounters and sexual abuse (Choi, Wong \& Fong, 2018; Fansher \& Randa, 2019; Marganski \& Melander, 2018).

Notwithstanding, the time spent on using online dating sites/apps was only significant for ghosting $(\mathrm{H} 2)$. This result could be explained by the fact that spending more time online would increase the likelihood of knowing potential partners (Chan, 2016). Consequently, starting more relationships could increase the risk of suffering or practicing ghosting when the expectations of one of the engaged partners are not met, and they could wish to end the relationship. Although both variables (use and time used) were statistically significant, their explanatory power was weak. So we were unable to conclude that ghosting and breadcrumbing are closely related conducts to relationships originated in the virtual world. In line with what previous reviews and studies into ghosting have pointed out, strategies to put an end to romantic relationships, and here we can also add strategies to maintain relationships, have been used prior to the use of online sites or smartphone apps, but computer-mediated communication may have helped to adopt more frequently non-direct confronting strategies like those formerly analyzed (Brody et al., 2016; LeFebvre, 2017). Nonetheless, previous research shows that breakup rates for marital and non-marital dating relationships are higher for couples who met online than for couples who met through offline venues (Paul, 2014). Thus, future research must analyze if differences appear in how ghosting and breadcrumbing are employed according to how the relationship was originated (offline or online), and if ghosting and breadcrumbing are more characteristic of one type of relationship or the other.

Former research demonstrates that ghosting is the most widespread strategy used in short-term relationships characterized by less commitment (Koessler et al., 2019). Along the same lines, the results of the present study revealed that having more short-term relationships is related with suffering and performing ghosting, and also breadcrumbing $(\mathrm{H} 3)$. If we consider that short-term relationships may be characterized by lack of commitment, or can be sporadic sexual encounters (e.g. hook-ups), technology can facilitate the processes to break up relationships given that they allow a dating relationship to end more easily if there are no emotional ties. The opposite is also possible. Those who perpetrate, or receive ghosting and breadcrumbing could be more inclined toward short-term relationships. For example, in the case of ghosting a series of short-term relationship are expected as one relationship has at least ended through ghosting. Breadcrumbing could also be facilitated because one of the involved partners could use it as a way to keep enjoying sporadic encounters without the relationship developing. As the potential of online dating sites and apps for finding a romantic and casual sex relationships is similar (Anzani et al., 2018; Bryant \& Sheldon, 2017), future research should analyze is there are differences in ghosting and breadcrumbing according to romantic or sexual motivations to form a relationship regardless of how long that relationship lasts. Previous research have shown that gay, bisexual and men who have sex with men have been using increasingly dating apps to meet anonymous partners and have sexual encounters (LeFebvre, 2018), and our results showed that LGB participants are being more exposed to ghosting and breadcrumbing. Future studies should examine if ghosting and breadcrumbing behaviors among LGB people are in some way related with the use of geosocial-networking apps to meet new sexual or romantic partners. It would also be interesting to analyze to what extent ghosting and breadcrumbing can be strategies adopted by people in committed relationships. Previous research shows that those who already have a partner use dating apps/sites to find casual sexual encounters, to satisfy their curiosity about today's dating market, and to know their worth as a potential partner compared to single users (Alexopous, Timmermans and McNallie, 2020). So it would be interesting to know how these motivations are related with strategies like ghosting and breadcrumbing. 
The results of the present study revealed that the amount of time between starting online contact and deciding to meet someone in person is not related to ghosting and breadcrumbing (H4). Despite former research has showed that shifting offline is related to the expectations toward a potential partner and perceptions of intimacy and composure in a relationships originated online (Ramirez et al., 2014), shifting offline is not apparently related to strategies to break up or maintain a dating partner. One possible explanation for this lack of association is that ghosting and breadcrumbing could take place regardless of the time chatting online, and even regardless of meeting in person. Thus ghosting could be a strategy used by those people who, at any point of the online contact, do not wish to tell the other person they do not like them or they do not meet their expectations, and wish to stop communicating to avoid direct confrontations (LeFebvre, 2017). Similarly, breadcrumbing can be a strategy adopted to delay meeting someone personally. That is, perhaps someone suffering breadcrumbing does not live up to the expectations of the person initiating it, (s)he does not find them attractive or does not know how to end the relationship, but wishes to continue if they do not know anyone who is a "better" alternative, and maintains him/her among their followers in social networks and to obtain their reinforcement as an "admirer". Future research must analyze if ghosting and breadcrumbing take place regardless of the people involved having known one another offline or otherwise. In other words, if it is more likely to occur after knowing someone in person, or also when relationships have only been virtually maintained. It would also be important to analyze the intentions of those who practice breadcrumbing and how their behaviors influence those suffering it.

Finally, the present results revealed that the participants using online surveillance in social networks with partners they have known online are more likely to be initiators and recipients of ghosting and breadcrumbing (H5). These results fall in line with those studies indicating that online surveillance can happen when relationships form, while they continue or as part of strategies used to end relationships (Tokunaga, 2011). As previous research reveals, online surveillance may have an influence in two directions as regards both the behavior of initiators and recipients of ghosting and breadcrumbing. Given that online surveillance can be used to assess authenticity and compatibility (Couch, Liamputtong \& Pitss, 2011), online surveillance can contribute to decision making about ending relationships or to avoid relationships developing when acquiring information from social networks allow to form a more accurate idea as to whether (s)he meets their expectations or not. Additionally, online surveillance can also be seen as a way to control by whoever suffers ghosting and breadcrumbing (Fox, 2016). Thus, ghosting and breadcrumbing can be a response to being monitored by someone, breaking someone's trust, generating toxicity or shaping a negative impression of those who starts ghosting or breadcrumbing. Future research must investigate the perception of initiators and recipients of online surveillance, their motivations to carry it out, and how both variables are related to ghosting and breadcrumbing. In this line, former qualitative research has shown that ghosting is sometimes a way of protecting from disrespect, aggressiveness, or even harassment (Manning et al., 2019). Future research must investigate the perception of initiators and recipients of online surveillance, their motivations to carry it out, and how both variables are related to ghosting and breadcrumbing.

\section{Limitations in the Present Study}

This study is not without its limitations, which should be taken into account when interpreting its results. First, we measured ghosting and breadcrumbing by only one question and we did not ask the participants about the relationship they maintain/had maintained with someone who had suffered or carried out both strategies. Future research should collect more detailed information about these conducts and the kind of relationship that was ended by ghosting or maintained by breadcrumbing (e.g. causal sexual encounters, short-term relationship, committed relationships). Second we limited the analysis done of practices related to online dating in order to know the time that had elapsed before knowing someone in person and the online surveillance of the people met online. So it would be relevant to learn if online surveillance is performed by people who initiate ghosting or breadcrumbing, or by those who receive them. Third, although the age range is quite wide, it would be interesting to acquire data from other age groups. Former research indicates that dating apps are becoming increasingly popular with other age groups, like seniors aged over 65 years (Anzani et al., 2018). Therefore, future research should include people over the age of 40 because they might also be exposed to these conducts. Finally, we collected all the data by cross-sectional self-report measures that we acquired online. This was why we were unable to make causal interpretations and we cannot be sure that the participants provided accurate information about their conducts on the Internet. 


\section{Conclusion}

Two in every 10 participants reported being involved in ghosting, and more than three in every 10 participants had been involved in breadcrumbing. Both conducts are related to using online dating sites/ apps and related practices like online surveillance. This study contributes to our knowledge about these digital tactics to end or maintain dating relationships, and helps us to understand part of the personal management that takes place with online dating in today's society.

\section{References}

1. Abramova, O., Baumann, A., Krasnova, H., \& Buxmann, P. (2016, January). Gender differences in online dating: what do we know so far? A systematic literature review. In 2016 49th Hawaii International Conference on System Sciences (HICSS) (pp. 3858-3867). IEEE. https://doi.org/10.1109/ HICSS.2016.481

2. Anzani, A., Di Sarno, M., \& Prunas, A. (2018). Using smartphone apps to find sexual partners: A review of the literature. Sexologies, 27, e61-e65. https://doi.org/10.1016/j.sexol.2018.05.001

3. Authors (2019). Psychological correlates of ghosting and breadcrumbing experiences: a preliminary study in adult relationships. International Journal of Environmental Research and Public Health [Under review].

4. Blackhart, G. C., Fitzpatrick, J., \& Williamson, J. (2014). Dispositional factors predicting use of online dating sites and behaviors related to online dating. Computers in Human Behavior, 33 , 113-118. https://doi.org/10.1016/j.chb.2014.01.022

5. Brody, N., LeFebvre, L. E., \& Blackburn, K. G. (2016). Social networking site behaviors across the relational lifespan: Measurement and association with relationship escalation and de-escalation. Social Media+ Society, 2, 2056305116680004. https://doi.org/10.1177\%2F2056305116680004

6. Bryant, K., \& Sheldon, P. (2017). Cyber Dating in the Age of Mobile Apps: Understanding Motives, Attitudes, and Characteristics of Users. American Communication Journal, 19, 1-15.

7. Cambridge Dictionary (2019, November 11). Breadcrumbs. Retrieved from https://dictionary.cambridge.org/es/diccionario/ingles/breadcrumbs

8. Cambridge Dictionary (2019, November 11). Ghosting. Retrieved from https://dictionary.cambridge.org/es/diccionario/ingles/ghosting

9. $\quad$ Chan, L.S. (2016). Predicting the intent to use dating apps to look for romance and sex: using the integrative model of behavioral prediction. Paper presented at International Communication Association Annual Conference, Fukuoka, Japan, June 9-13.

10. Chen, M., Cheung, S. Y., \& Chan, K. L. (2019). Doxing: what adolescent look for and their intentions. International Journal of Environmental Research and Public Health, 16, 218. https://doi. org/10.3390/ijerph16020218

11. Choi, E. P. H., Wong, J. Y. H., \& Fong, D. Y. T. (2018). An Emerging Risk Factor of Sexual Abuse: The Use of Smartphone Dating Applications. Sexual Abuse, 30, 343-366. https://doi. org/10.1177/1079063216672168

12. Cook, K. (2020). Mental Health, Relationships \& Cognition. In The Psychology of Silicon Valley (pp. 197-233). Palgrave Macmillan, Cham. https://doi.org/10.1007/978-3-030-27364-4 8

13. Couch, D., Liamputtong, P., \& Pitts, M. (2011). Online Daters and the Use of Technology for Surveillance and Risk Management. International Journal of Emerging Technologies \& Society, 9, 116-134.

14. Fansher, A. K., \& Randa, R. (2019). Risky social media behaviors and the potential for victimization: a descriptive look at college students victimized by someone met online. Violence and gender, 6, 115-123. https://doi.org/10.1089/vio.2017.0073

15. Finkel, E. J., Eastwick, P. W., Karney, B. R., Reis, H. T., \& Sprecher, S. (2012). Online dating: A critical analysis from the perspective of psychological science. Psychological Science in the Public interest, 13, 3-66. https://doi.org/10.1177\%2F1529100612436522

16. Fox, J. (2016). 7. The Dark Side of Social Networking Sites in Romantic Relationships. In B.K. Wiederhol, G. Riva, \& P. Cipresso (Eds.), The Psychology of Social Networking: communication, presence, identity, and relationships in online communities (pp. 78-89). Berlin, Germany: DeGruyter Open.

17. Fox, J., Osborn, J. L., \& Warber, K. M. (2014). Relational dialectics and social networking sites: The role of Facebook in romantic relationship escalation, maintenance, conflict, and dissolution. Computers in Human Behavior, 35, 527-534. https://doi.org/10.1016/j.chb.2014.02.031 
18. Fox, J., \& Warber, K. M. (2014). Social networking sites in romantic relationships: Attachment, uncertainty, and partner surveillance on Facebook. Cyberpsychology, Behavior, and Social Networking, 17, 3-7. https://doi.org/10.1089/cyber.2012.0667

19. Freedman, G., Powell, D. N., Le, B., \& Williams, K. D. (2019). Ghosting and destiny: Implicit theories of relationships predict beliefs about ghosting. Journal of Social and Personal Relationships, 36, 905-924. https://doi.org/10.1177\%2F0265407517748791

20. Gini, G., Marino, C., Xie, J., Pfetsch, J., \& Pozzoli, T. (2019). Associations of Traditional and Peer Cyber-Victimization With Adolescents' Internet Use: A Latent Profile Analysis. Cyberpsychology: Journal of Psychosocial Research on Cyberspace, 13, article 1. http://dx.doi.org/10.5817/ CP2019-4-1

21. Goedel, W. C., Mitchell, J. W., Krebs, P., \& Duncan, D. T. (2017). Willingness to use mobile phone apps for HIV prevention among men who have sex with men in London: web-based survey. JMIR mHealth and uHealth, 5, e153. https://doi.org/10.2196/mhealth.8143

22. Gómez, P., Rial, A., Braña, T., Golpe, S., \& Varela, J. (2017). Screening of Problematic Internet Use among Spanish adolescents: Prevalence and related variables. Cyberpsychology, Behavior, and Social Networking, 20, 259-267. https://doi.org/10.1089/cyber.2016.0262

23. Growth from Knowledge, GFK (2019). Estudio GfK sobre Plataformas de Citas online en España [GfK Survey on Online Dating Platforms in Spain] [online] Retrieved from: https://insights.gfk.com/ paginas-de-citas

24. Hahn, H. A., You, D. S., Sferra, M., Hubbard, M., Thamotharan, S., \& Fields, S. A. (2018). Is it too soon to meet? Examining differences in geosocial networking app use and sexual risk behavior of emerging adults. Sexuality \& Culture, 22, 1-21. https://doi.org/10.1007/s12119-017-9449-3

25. Hobbs, M., Owen, S., Gerber, L. (2017). Liquid love? Dating apps, sex, relationships ad the digital transformation of intimacy. Journal of Sociology, 53, 271-284. https://doi. org/10.1177/1440783316662718

26. labSpain (2019). Estudio annual de redes sociales 2019 [Annual study of social networks sites 2019] [online] Retrieved from: https://iabspain.es/wp-content/uploads/2019/06/estudio-anual-redes-sociales-iab-spain-2019_vreducida.pdf

27. Koessler, R.B., Kohut, T., \& Campbell, L. (2019). When boo becomes a ghost: the association between breakup strategy and breakup role in experiences of relationship dissolution. Collabra: Psychology, 5, 29. https://doi.org/10.1525/collabra.230

28. Lawson, H. M., \& Leck, K. (2006). Dynamics of internet dating. Social Science Computer Review, 24, 189-208. https://doi.org/10.1177\%2F0894439305283402

29. LeFebvre, L.E. (2017). Phantom lovers: Ghosting as a relationship dissolution strategy in the technological age. In N. M. Punyanunt-Carter \& J.S. Wrench (Eds.), The impact of social media in modern romantic relationships (pp. 219-235). New York, NY: Lexington Books.

30. LeFebvre, L.E., Allen, M., Rasner, R.D., Garstad, S., Wilms, A., \& Parrish, C. (2019). Ghosting in emerging adutl's romantic relationships: the digital dissolution disappearance strategy. Imagination, cognition and personality: consciousness in theory, research, and clinical practice, 39, 125-150. https://doi.org/10.1177/0276236618820519

31. LeFebvre, L. E. (2018). Swiping me off my feet: Explicating relationship initiation on Tinder. Journal of SocialandPersonal Relationships, 35, 1205-1229. https://doi.org/10.1177\%2F0265407517706419

32. Manning, J., Denker, K.J., \& Johnson, R. (2019). Justifications for "ghosting out" of developing or ongoing romantic relationships: anxieties regarding digitally-mediated romantic interaction. In A. Hetsroni, A. \& M. Tuncez (Eds.). It happen on tinder. Reflections and studies on Internet-infused dating (pp. 114-132). Institute of Network Cultures: Amsterdam, 2019,

33. Marganski, A., \& Melander, L. (2018). Intimate partner violence victimization in the cyber and real world: Examining the extent of cyber aggression experiences and its association with in-person dating violence. Journal of Interpersonal Violence, 33, 1071-1095. https://doi. org/10.1177/0886260515614283

34. Martínez-Ferrer, B., Moreno, D., \& Musitu, G. (2018). Are adolescents engaged in the problematic use of social networking sites more involved in peer aggression and victimization? Frontiers in Psychology, 9, article 801. https://doi.org/10.3389/fpsyg.2018.00801

35. Meenagh, J. (2015). Flirting, dating, and breaking up within new media environments. Sex Education, 15, 458-471. https://doi.org/10.1080/14681811.2015.1033516

36. Menkin, J. A., Robles, T. F., Wiley, J. F., \& Gonzaga, G. C. (2015). Online dating across the life span: Users' relationship goals. Psychology and aging, 30, 987-993. https://doi.org/10.1037/ a0039722 
37. Moore, P. (2014, October 28). Poll results: Ghosting. Retrieved from https://today.yougov.com/ topics/lifestyle/articles-reports/2014/10/28/poll-results-ghosting

38. Paul, A. (2014). Is online better thatn offline for meeting partners? Depends: are you looking to marry or to date? Cyberpsychology, Behavior, and Social Networking, 17, 1-4. https://doi. org/10.1089/cyber.2014.0302

39. Prestage, G., Bavinton, B., Grierson, J., Down, I., Keen, P., Bradley, J., \& Duncan, D. (2015). Online dating among Australian gay and bisexual men: romance or hooking up? AIDS and Behavior, 19, 1905-1913. https://doi.org/10.1007/s10461-015-1032-z

40. Pronk, T. M., \& Denissen, J. J. (2019). A Rejection Mind-Set: Choice Overload in Online Dating. Social Psychological and Personality Science. https://doi.org/10.1177\%2F1948550619866189

41. Ramirez, A., Sumner, E. M., Fleuriet, C., \& Cole, M. (2014). When online dating partners meet offline: The effect of modality switching on relational communication between online daters. Journal of Computer-Mediated Communication, 20, 99-114. https://doi.org/10.1111/jcc4.12101

42. Rosenfeld, M. J., Thomas, R. J., \& Hausen, S. (2019). Disintermediating your friends: How online dating in the United States displaces other ways of meeting. Proceedings of the National Academy of Sciences, 116, 17753-17758. https://doi.org/10.1073/pnas.1908630116

43. Stoicescu, M. (2019). The globalized online dating culture: Reframing the dating process through online dating. Journal of Comparative Research in Anthropology and Sociology, 10, 21-32.

44. The Telegraph (2015, November, 5). Binge-watch', 'clean eating' and 'manspreading' among 2015 Words of the Year. Retrieved from: https://www.telegraph.co.uk/news/newstopics/howaboutthat/11975734/Binge-watch-clean-eating-and-manspreading-among-2015-Words-of-the-Year. $\underline{\mathrm{html}}$

45. The New York Times (2016, July 8). The agony of the digital tease. Retrieved from https://www. nytimes.com/2016/07/10/fashion/dating-text-messages-breadcrumbing.html? $r=1$

46. Tokunaga, R. S. (2011). Social networking site or social surveillance site? Understanding the use of interpersonal electronic surveillance in romantic relationships. Computers in Human Behavior, 27, 705-713. https://doi.org/10.1016/j.chb.2010.08.014

47. Tong, S. T. (2013). Facebook use during relationship termination: Uncertainty reduction and surveillance. Cyberpsychology, Behavior, and Social Networking, 16, 788-793.

48. https://doi.org/10.1089/cyber.2012.0549

49. Urban dictionary (2019, November 27). Breadcrumbing. Retrieved from https://www.urbandictionary.com/define.php?term=Breadcrumbing

50. Villora, B., Navarro, R., \& Yubero, S. (2019). Cyber dating abuse and its association with mobile abuse, acceptance of violence and myths of love. Suma Psicológica, 26, 46-54. http://dx.doi. org/10.14349/sumapsi.2019.v26.n1.6

51. Waterloo, S. F., Baumgartner, S. E., Peter, J., \& Valkenburg, P. M. (2018). Norms of online expressions of emotion: Comparing Facebook, Twitter, Instagram, and WhatsApp. New Media \& Society, 20, 1813-1831. https://doi.org/10.1177/1461444817707349

RECIBIDO: 17 de julio de 2020

MODIFICADO: 24 de noviembre de 2020

ACEPTADO: 16 de diciembre de 2020 